\title{
Modelling of heat and mass transfer in water pool type storages for spent nuclear fuel
}

\author{
E. Fedorovich, A. Pletnev \& V. Talalov \\ Department of Physics and Mechanics, \\ Saint-Petersburg State Polytechnic University, Russian Federation
}

\begin{abstract}
The organization of heat removal from spent nuclear fuel in "wet" type storages is discussed. The heat- and mass-transfer processes (natural and mixed connection of water coolant, evaporation of water) under normal and accident situations in storages are considered. Special attention is devoted to the mathematical and physical modelling of the above mentioned processes.

Keywords: heat mass transfer, nuclear spent fuel, water pool type storage, mixed convection, evaporation, accident situation, mathematical and physical modelling.
\end{abstract}

\section{Introduction}

From thermophysical point of view each storage is a heat generating system (due to residual energy release in radioactive decay processes) which has mass and heat exchange with environment.

"Wet" type storage represents pools in which SNFA are immersed into. For the additional protection of the pool water from the direct contact with the cladding of highly radioactive fuel rods, the SNFAs can be placed in metal cans, which are also water filled. These cans are opened from above, which allows water free expansion and adding water to them by its evaporation. Such a construction of WS is used at Leningradskaya NPP near S. Petersburg, Russia (fig. 1). Pool water with the temperature of $30-40^{\circ} \mathrm{C}$ is pumped from the bottom of pool compartments to the external system of cooling and purification and returns cooled up to $20-30^{\circ} \mathrm{C}$ flowing into the regions near upper water level. The water of pool evaporates into ventilating air flow, sucked into the space between upper water level and metal floor of a storehouse. Maximum 
temperatures of pool's water are fixed in its upper part (fig. 1). Fact of temperature stratification leads to conclusion, that the natural convection is a dominant process in mixed convection heat transfer in water volume.
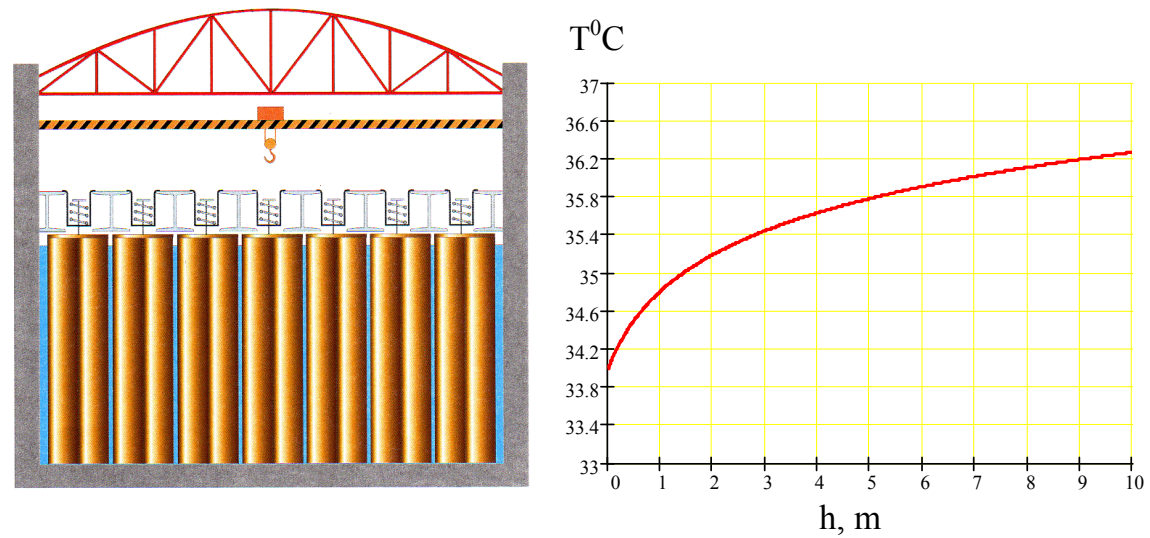

Figure 1: Water pool type SNF storage at Leningradskaya NPP and water temperatures distribution along the height of the pool.

The magnitude of heat removal from SNF by water is defined by simultaneous accomplishment of the following processes:

- mixed convection in the close vertical bundles, formed by rows of heat generating fuel rods (or cans) and forced water flow from above to down or in opposite direction;

- evaporation from upper water levels (in pool and in cans, if last ones are used);

- "pure" free convection inside cans, when directed movement of water is absent, because cans are closed from beneath.

\section{Physical modelling of the counter flow mixed convection in a pool}

\subsection{Test section and experimental facility}

The body of the test section (fig. 2) is manufactured from the organic glass. It presents itself as a vertical box of rectangular cross section $132 \times 118 \mathrm{~mm}$ and height $1070 \mathrm{~mm}$. In upper part of body the water inlet collector (13) is placed. The cans with SNFA (or fuel rods inside can) are modeled by the electrically heated 56 stainless steel tubes with diameter $10 \mathrm{~mm}$, arranged at corridor order $(8 \times 7)$. Upper part of the tube bundle with length of $360 \mathrm{~mm}$ is made from brass, has negligible electrical resistance and joule heat generation and forms a hydraulic stabilization part of a channel. The temperature of tubes is measured by thermocouples (5), placed inside tubes. Maximal electric power of the heater - $5 \mathrm{~kW}$. The distance between tubes axises $-4 \mathrm{~mm}$, so the narrowest gap between them is $4 \mathrm{~mm}$. The flow rate through test section is controlled by the 
valve (19). It is possible to heat inlet water flow by electric heater in upper water tank (20). The outer surface of the body is thermally isolated, but isolation can be easily removed for visual observation of water flow.

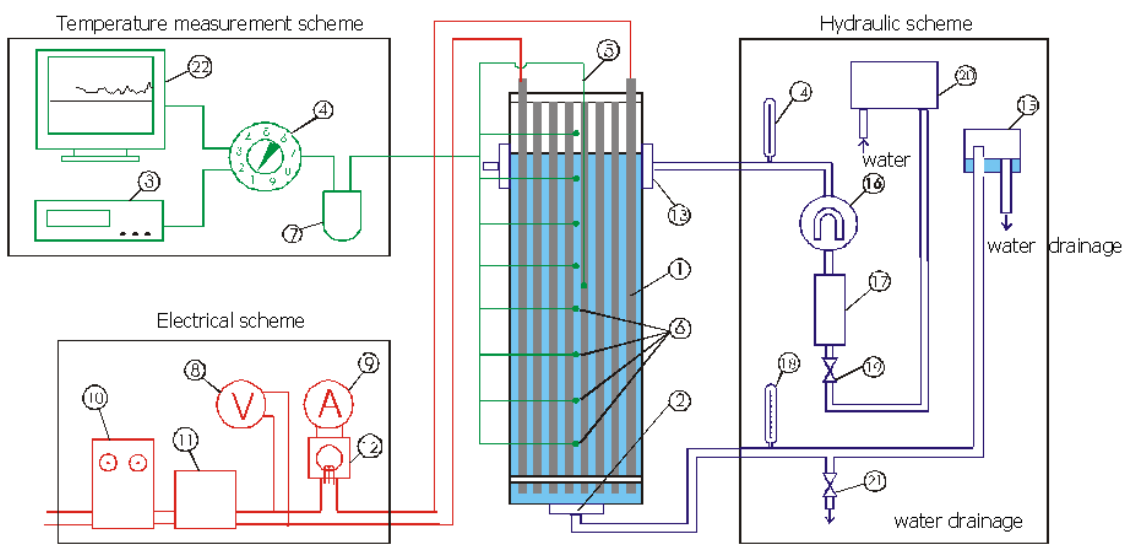

1 - shell of test section (organic glass with outer sizes 132 × 118 x $1070 \mathrm{~mm}$ ); 2 -heated tubes; 3 -digital millivoltmeter for thermocouples signals registration; 4 -thermocouples switch; 5-moved thermocouple for measuring temperature of tubes; 6-8 moved thermocouples far water temperatures measuring along and across of test section; 7-Dewar with constant temperatures of "cold" contacts of thermocouples; 8 -voltmeter of electrical power supply system; 9 - amperemeter of that system; 10 - primary controlled autotransformer; 11 - secondary power supply transformer; 12 - transformer of electrical current; 13 - water supply collector with flow uniform distribution nozzle device; 14, 18 - thermometers for water inlet and outlet temperatures measuring; 15 - moved water vessel, providing necessary level of water in test section and supplied by electrical heater of water; 16 - reversed U-type reometer for water flow rate measurements; 17 -filter for water purification; 19-drainage valve; 20-tank-damper for water dearation and flow rate stabilization; 21 - drainage valve; 22 - computer equipped with ADT card.

Figure 2: $\quad$ Scheme of test section and experimental facility.

\subsection{Experimental methodics}

The stability of water flow through model has been provided with high accuracy ( $\pm 1 \%$ ) due to use of the head tank with constant water level. The entering water was undergone constant cleaning. The local tubes and water temperatures have been registered at four cross sections along model's height. The physical properties of water during the data treatment have been taken at mean ariphmetic values from water inlet and outlet temperatures. The values of local heat fluxes densities depend on the local joule heat releases in the electrically heated tubes. That's why the special measurements of the each tube electrical resistance were 
conducted and their temperature dependence was found. Additionally threedimensional computer program has been developed for the calculation of electrical potential distribution in the heater elements (upper brass tubes, stainless steel heating tubes, electrical soldered contacts) and in the water between tubes. Usage of this program allows to take into account the role of electrical conductivity of water (and consequently part of heat, generating in water volume) in whole heat flux production and to evaluate the role of reactivity electrical power losses in whole test section heat balance.
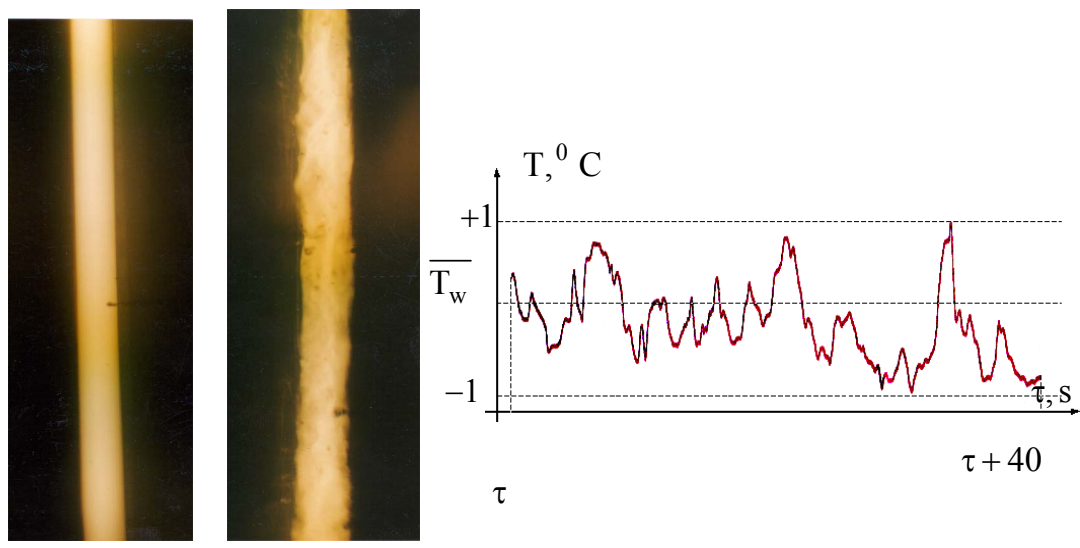

"cold" mode test mode

Figure 3: Picture of flow in gap between heat generating rods (tubes) and water temperature oscillations inside gap.

The experimental data processing program allows also the possibility to determine the temperature drops across tubes walls thickness. With heater powers level less than $500 \mathrm{~W}$ this drop was less than $0.015 \mathrm{~K}$, but with higher powers (close to $4-5 \mathrm{~kW}$ ) temperature drop in steel wall can form up to $10 \%$ from overall temperature difference and consequently should be taken in account in data processing. By each experiment performance the heat balance of the test section was reduced with taking into account heat release in heater elements and water, the amount of heat, absorbed by water flow and heat losses to environment. The accuracy of heat balance reducing was not worse, than $2 \%$. Special attention was given to the uniform flow distributions at water supply on the upper water level. With this aim the upper distributing collectors was used in a form of 14 tubes with 3 openings in each tube. The temperature difference between tubes and water were measured by hyperdifferthermocouples. Their signals were directed to analogous-figure transformer through an amplifier for the following treatment. During experiments the local water temperature oscillations were registered. Their amplitudes have reached about $50 \%$ of the "wall-water" temperature differences (fig. 3). It shows the significant turbulence in a space between heated rods. 


\subsection{Experimental results}

The results for mixed convection heat transfer are plotted in coordinates [1g $\left.\left(\mathrm{Nu} / \mathrm{Nu}_{0}\right) ; \lg \left(\mathrm{Ra}_{\mathrm{q}} / \mathrm{Re}\right)\right]$ (fig. 4). They related to the next dimensionless parameters ranges: $\mathrm{Re}=28-125 ; \mathrm{Ra}_{\mathrm{q}}=4,5 \cdot 10^{5}-1,6 \cdot 10^{7} ; \mathrm{Pr}=2,5-8,8$. In these ranges the correlation between them can be presented in a convenient for the practical use form:

$$
\mathrm{Nu} / \mathrm{Nu}_{0}=1 / 3 \cdot\left(\mathrm{Ra}_{\mathrm{q}} / \mathrm{Re}\right)^{1 / 3},
$$

which is found by the least square method.

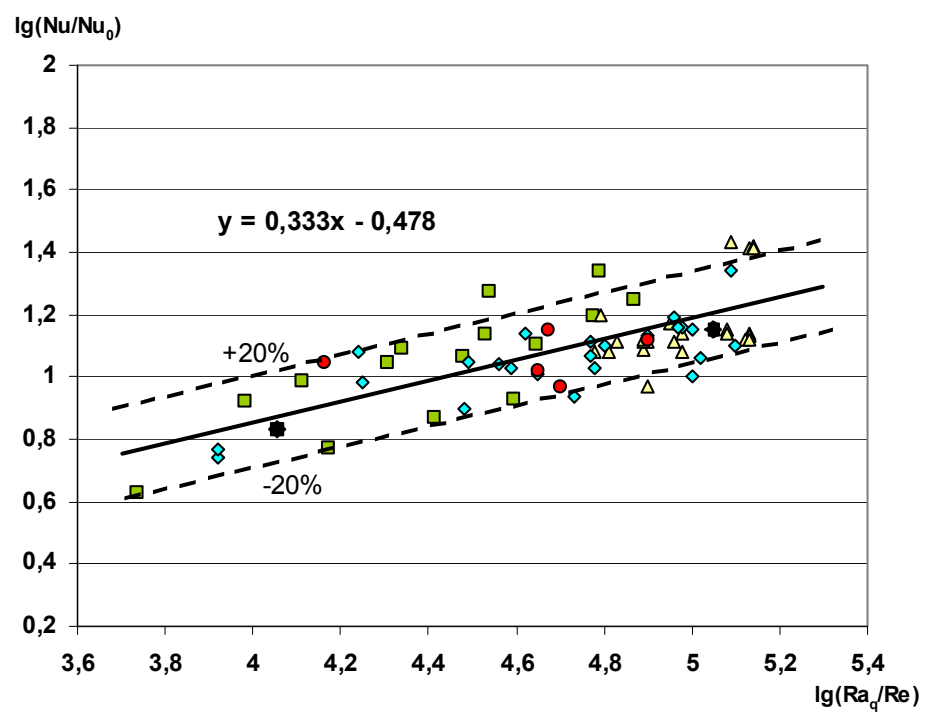

口, $\Delta, \diamond, \circ-$ different experiments series; $\bullet$-Petukhov and Strigin correlation [10].

Figure 4: Heat transfer by counter flow mixed convection of water in vertical bundle of heat generating rods.

As also can be seen from fig. 4 our data are in good agreement with Petukhov and Strigin's correlation formula $[3,7,10]$. Their data have been obtained for the counter-flow mixed "turbulent" convection of the water inside vertical tube and their correlation was recommended for diapasons: $3 \cdot 10^{2} \leq \operatorname{Re} \leq 2,5 \cdot 10^{4} ; 5 \cdot 10^{3}<$ $\mathrm{Ra}_{\mathrm{q}}<1,3 \cdot 10^{7} ; 2 \leq \operatorname{Pr} \leq 6$. It is interesting to remark, that this agreement is discovered, despite of the considerable difference in Reynolds numbers minimum of $\operatorname{Re} \cong 300$ in the work [10] and maximum of $\operatorname{Re} \cong 120$ in our work. That circumstance can be explained by the similarity in physical processes of both cases, when a role of turbulent mass and heat transfer is a dominant one in overall transfer mechanism despite of low values of a mass flux. In our case 
we falled up to Reynolds numbers $\sim 30$. Such flow rate velocities are typical for SNF storage pools. This supposition is supported by our visual observations of the flow inside the inter-tube gaps (see fig. 3). It was seen the visible vortexes formation in the gap space, which is disappeared with model heating stop.

It is interesting to compare received data with a theoretical value of Nusselt number for the laminar flow in rod bundle $\mathrm{Nu}_{\mathrm{lam}}$. According to the work [15] the $\mathrm{Nu}_{\text {lam }}$ number for the square type arrow with the ratio $\mathrm{S} / \mathrm{d}=1,4$ is equal $\mathrm{Nu}_{\text {lam }}=7,7$ (boundary condition $\mathrm{q}=$ Const). For $\mathrm{Ra}_{\mathrm{q}}$ numbers corresponding to temperature oscillation rise $\left(\mathrm{Ra}_{\mathrm{q}} \sim 2,1 \cdot 10^{6}\right)$ the Nusselt numbers in our experiments were equal to $\sim 30$. It shows, that the heat transfer augmentation effect due to thermogravitational forces at the boundary of vortexes generation was about $30 / 7,7 \cong 3,9$.

\section{Evaporation from pools and cans}

Intensity of evaporation is defined by the rate of vapor extraction from the water surface. Vapour flow density $g$ in the boundary layer near the surface is defined by diffusion and Stephen flow $[17,19]$ and expressed by the formula:

$$
\overrightarrow{\mathrm{g}}=-\frac{\mathrm{MPD}}{\mathrm{RT}} \cdot \frac{1}{1-\mathrm{Y}} \cdot \operatorname{grad} \mathrm{Y}=\frac{\mathrm{MPD}}{\mathrm{RT}} \cdot \operatorname{grad}[\ln (1-\mathrm{Y})]
$$

where

$\mathrm{M}$ - molecular weight of vapour; $\mathrm{P}$ - total pressure (atmosphere); D - diffusion coefficient of vapour in the air; $\mathrm{R}$ - absolute gas constant; $\mathrm{T}$ - absolute temperature; $Y=p_{n} / P$, where $p_{n}-$ partial vapour pressure. The full heat flux from water per unit of area is

$$
\overrightarrow{\mathrm{q}}_{\text {full }}=\overrightarrow{\mathrm{g}}_{0} \cdot \mathrm{r}+\overrightarrow{\mathrm{q}}_{0}
$$

where $\overrightarrow{\mathrm{g}}_{0}$ and $\overrightarrow{\mathrm{q}}_{0}$ are mass flux and heat flux at the surface: $\mathrm{r}-$ specific heat of evaporation.

Considering the processes in the boundary layer it's necessary to introduce the values of mass transfer $\beta$ and heat transfer $\alpha$ coefficients defined by the following expressions:

$$
\beta=\frac{\mathrm{g}}{\rho_{\text {red }}^{\prime \prime} \cdot\left(\mathrm{Y}_{0}-\mathrm{Y}_{\text {flow }}\right)} \quad \text { and } \quad \alpha=\frac{\mathrm{q}}{\mathrm{T}_{0}-\mathrm{T}_{\text {flow }}}
$$

where $\mathrm{Y}_{0}=\frac{\mathrm{p}_{0}^{\prime \prime}}{\mathrm{P}} ; \mathrm{Y}_{\text {flow }}=\frac{\mathrm{p}_{\text {flow }}^{\prime \prime}}{\mathrm{P}}, \mathrm{p}_{0}^{\prime \prime}$ - partial vapour pressure near the water surface equal to the saturation pressure at the temperature surface $\mathrm{T}_{0} ; \mathrm{p}_{\text {flow }}-$ vapour partial pressure in the flow with the temperature $\mathrm{T}_{\text {flow }} ; \rho_{\text {red }}^{\prime \prime}=\frac{\mathrm{MP}}{\mathrm{R} \cdot \overline{\mathrm{T}}}-$ vapour density, reduced to the pressure $\mathrm{P}$ and defining temperature of the 
boundary layer $\overline{\mathrm{T}}$. It often happens when only one of the coefficients is known ( $\alpha$ or $\beta$ ). Then for the calculation of the second coefficient it's possible to use heat and mass exchange process similarity, expressed by the equation:

$$
\frac{\alpha}{\beta}=\frac{\lambda}{D} \cdot f(\text { Le })
$$

where $\mathrm{Le}=\frac{\mathrm{D}}{\mathrm{a}}$ is Lewis number $(\lambda-$ heat conductivity of mixture, a - air-vapour mixture thermal diffusivity coefficient). In the simplest case, when Le $=1$, the value $\frac{\lambda}{D}=\frac{\lambda}{a}=\rho \cdot c_{p}$ and $f(L e)$ is also equal to 1 . For conditions heat removal of the water surface in the pools which are close to the conditions of evaporative water cooling in cooling towers [17] $\mathrm{Le} \approx 1,2$ and $\mathrm{f}(\mathrm{Le})=\mathrm{Le}^{0,4}$.

By increasing the temperature of the supplied air (hot season) the role of convective heat flux will be lower, and the part of the evaporating heat removal will be risen.

\section{Accidental process in "wet" storage after water calculation termination}

The scheme of the thermal two - dimensional computation model, corresponding to this problem, is shown at fig. 5. In this scheme the elementary model cell of WS pool is, in fact, reduced to one SNFA "micro storage", which contents all participating in heat mass transfer elements of actual storage, e.g. fuel rods, can with SNFA, water inside a can, pool's water and pool's constraining constructions (walls, bottom, metal list above water level). So, one can expect, that after determination specific parameters of nonstationary process, namely amounts of heat removal and evaporated water related to one cell and after following multiplication these specific parameters on overall number of SNFAs in storage, these parameters for whole storage will be found. In this model all sizes of the can are kept as real ones, but intercan space are modeled by annular channel, which is more simple for the consideration, but similar in heat transfer process development. All sizes of the volumes, external in relation to the single can is chosen in a way, when the cross-sections areas of the intercan space and concrete side restrictions in model and in real storage would be equal. The wideness of two heat generating rings, modeling two rows of fuel rods inside SNFA (such is geometry of SNFA of RBMK - type reactor), is chosen in a way, when evaporation mirrors inside can in model and in natural storage also would be equal. The conditions of thermal modelling consist in the equality of Bio criteria for model and real object and in the recalculation of Fourier criteria, taking into account the difference between thicknesses of restriction concrete walls in reduced to single SNFA model and real pool. 


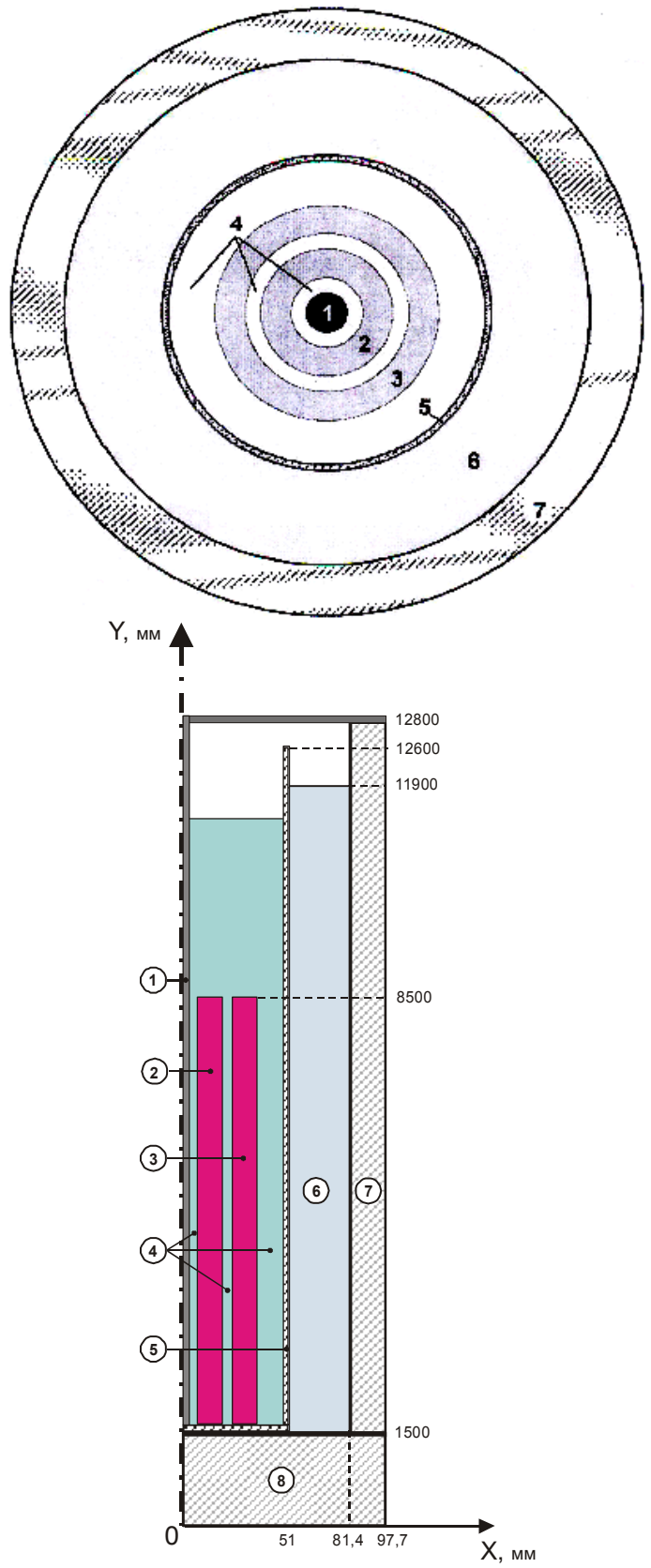

1- central supporting rod; 2, 3 - rows of fuel rods; 4 - water inside canister; 5 - canister wall; 6 - water outside canister; 7 - wall of pool

Figure 5: Scheme of the thermal two-dimensional computation model of a pool (accident situation analysis). 
In above described model the boundary "water - air" is movable one and is beneathing step by step due to evaporation from pool and from cans.

System of heat mass-transfer equations including equations of movement, written in cylindrical coordinates with taking into account physical properties of media with temperature, have appearance:

$(\mathrm{x}$ - radial coordinate, $\mathrm{y}$ - axial coordinate $)$

$$
\begin{gathered}
c \cdot \rho \cdot \frac{\partial T}{\partial \tau}=\frac{1}{x} \cdot \frac{\partial}{\partial x}\left(x \lambda \frac{\partial T}{\partial x}-c \rho U x T\right)+\frac{\partial}{\partial y}\left(\lambda \frac{\partial T}{\partial y}-c \rho V T\right)+Q_{V} ; \\
\frac{\partial C}{\partial \tau}=\frac{1}{x} \cdot \frac{\partial}{\partial x}\left(x D \frac{\partial C}{\partial x}-U x C\right)+\frac{\partial}{\partial y}\left(D \frac{\partial C}{\partial x}-V C\right) ; \\
\rho \cdot\left(\frac{\partial U}{\partial \tau}+U \frac{\partial U}{\partial x}+V \frac{\partial U}{\partial y}\right)=-\frac{\partial P}{\partial x}+2 \mu \frac{1}{x}\left(\frac{\partial U}{\partial x}-\frac{U}{x}\right)+2 \frac{\partial}{\partial x}\left(\mu \frac{\partial U}{\partial x}\right)+ \\
+\frac{\partial}{\partial y}\left[\mu\left(\frac{\partial U}{\partial y}+\frac{\partial V}{\partial x}\right)\right]+\rho F_{x} ; \\
\rho \cdot\left(\frac{\partial V}{\partial \tau}+U \frac{\partial V}{\partial x}+V \frac{\partial V}{\partial y}\right)=-\frac{\partial P}{\partial y}+\frac{\mu}{x}\left(\frac{\partial V}{\partial x}-\frac{\partial U}{\partial y}\right)+2 \frac{\partial}{\partial y}\left(\mu \frac{\partial V}{\partial y}\right)+ \\
+\frac{\partial}{\partial x}\left[\mu\left(\frac{\partial U}{\partial y}+\frac{\partial V}{\partial x}\right)\right]+\rho F_{y} ; \\
\frac{1}{x} \frac{\partial(x U)}{\partial x}+\frac{\partial V}{\partial y}=0 ; \quad \vec{F}=\vec{g} \cdot \beta \cdot\left(T_{a}-T\right) .
\end{gathered}
$$

System (11) is solved by finite differences numerical method at following boundary conditions:

- at the solid surfaces - conditions of "sticking " $(U=0 ; V=0)$;

- at the boundary line "water - moistured air" the normal velocity components are equal to zero $(\mathrm{V}=0)$ and tangential stresses are absent $(\partial \mathrm{U} / \partial \mathrm{y}=0)$; that corresponds to the absence of the above - water level space ventilation (conservative evaluation);

- at the boundary line "water-steam-air-mixture" and near the upper metal floor, which is cooled by the natural air convection inside storehouse, the steam is saturated, but at the final stages of accident process the steam pressure near floor may be less than saturation pressure;

- at the outer boundary of concrete wall of a pool the boundary condition of third type is specified:

$$
-\lambda \cdot \frac{\partial \mathrm{T}}{\partial \mathrm{x}}=\alpha_{\mathrm{env}} \cdot\left(\mathrm{T}-\mathrm{T}_{\mathrm{env}}\right) ;
$$


- the temperature at the lower boundary of a computational region is constant and is equal to the average through year temperature of a soil under bottom (fundament) of a pool.

The solution the system (11) is reduced by integer processes to the integral heat balance equation for storage and for each moment of time:

$$
\sum \mathrm{Q}_{\mathrm{SNFA}}=\mathrm{Q}_{\mathrm{h}}+\mathrm{Q}_{\mathrm{ev}}+\mathrm{Q}_{\mathrm{tr}}-\text { Qcond },
$$

where $\sum \mathrm{Q}_{\mathrm{SNFA}}$ - sum of all SNFAs heat generations, $\mathrm{Q}_{\mathrm{h}}$ - power of all constructions and media heating; $\mathrm{Q}_{\mathrm{ev}}$ - heat removal from SNFS with evaporated water; $\mathrm{Q}_{\mathrm{tr}}$ - heat transmitted to the environment through boundaries due to heat conductivity, convection, thermal radiation and with ventilating air; $\mathrm{Q}_{\text {cond }}-$ returned heat due to steam condensation on the colder in comparison with water solid surfaces.

In expression (13) the value of $\sum \mathrm{Q}_{\mathrm{SNFA}}$ is specified and members $\mathrm{Q}_{\mathrm{h}}, \mathrm{Q}_{\mathrm{ev}}$, $\mathrm{Q}_{\text {tr }}$ and $\mathrm{Q}_{\text {cond }}$ are calculated.

For system (11) solving and finding of equation (13) components it is necessary to have closing empirical correlations for the heat-mass-transfer coefficients. For that in several cases the literature data is possible to use, but sometimes is necessary special experiments to perform with specific processes conditions modelling. Such specific form of pool's water flow for normal operation conditions and for the initial moment of the accident process is a combination of natural and forced convection (mixed convection which is above discussed).

\section{Nomenclature and abbreviations}

$\mathrm{d}$ - outer diameter of a can with SNFA or heated tube of experimental model, $\mathrm{mm} ; \mathrm{d}_{\mathrm{eq}}=4 \mathrm{~F} / \mathrm{P}$, where $\mathrm{F}$ - cross section area of the elementary cell, formed by four neighboring cans (tubes, rods), $\mathrm{P}$ - wetted heated perimeter of tubes outer surfaces part, which is in contact with water in one cell,m; $\mathrm{g}$ - gravity acceleration, $\mathrm{m} / \mathrm{s}^{2} ; \rho$ - water density, $\mathrm{kg} / \mathrm{m}^{3} ; \alpha$ - heat-transfer coefficient, $\mathrm{w} /\left(\mathrm{m}^{2} \cdot \mathrm{K}\right) ; \lambda$ - water heat conductivity, $\mathrm{W} /\left(\mathrm{m}^{2} \cdot \mathrm{K}\right) ; \mathrm{v}$ - kinematic viscosity, $\mathrm{m} / \mathrm{s}$; $\mathrm{q}$ - heat flux density, $\mathrm{w} / \mathrm{m}^{2} ; \beta$ - water thermal expansion coefficient, $1 / \mathrm{K} ; \Delta \mathrm{t}-$ temperature difference "wall-liquid", $K ; \mathrm{Gr}=\frac{\mathrm{g} \beta \cdot \Delta \mathrm{t} \cdot \mathrm{d}_{\mathrm{eq}}^{3}}{\mathrm{v}^{2}}-$ Grashof number; $\mathrm{Gr}_{\mathrm{q}}=\frac{\mathrm{g} \beta \cdot \mathrm{d}_{\mathrm{eq}}^{4} \cdot \mathrm{q}}{\mathrm{v}^{2} \cdot \lambda}-$ modified Grashof number; $\mathrm{a}-$ thermal diffusity coefficient, $\mathrm{m} / \mathrm{s} ; \mathrm{P}_{\mathrm{r}}=\mathrm{V} / \mathrm{a}-$ Prandtl number; $\mathrm{Ra}_{\mathrm{q}}=\mathrm{Gr}_{\mathrm{q}} \cdot \mathrm{P}_{\mathrm{r}}-$ modified Ryleigh number; $\mathrm{w}-$ water velocity, $\mathrm{m} / \mathrm{s} ; \quad \operatorname{Re}=\frac{\mathrm{w} \cdot \mathrm{d}_{\mathrm{eq}}}{\mathrm{v}} \quad-\quad$ Reynolds number; 
$\mathrm{Nu}=\frac{\alpha \cdot \mathrm{d}_{\mathrm{eq}}}{\lambda}-$ Nusselt number. Abbreviations: SNF(A) - spent nuclear fuel (assembly); SNFS - spent nuclear fuel storage; WS - "wet" type storage; NPP nuclear power plant.

\section{References}

[1] Lambert R.W. (EPRI) Storage Experience, United States of America, BEFAST-III Conference, Toronto, Canada, Oct. 19-23, report RWL-P9901, 1992.

[2] Lambert J.D.B., Lambert R., Spent Fuel at commercial U.S. Reactors - an overview (ANL,EPRI), Proceedings of Advanced Research Workshop "Safety-related issues of spent nuclear fuel storage”, September 26-29, Almaty, Republic of Kazakhstan, p. 24, 2005. (in English).

[3] Kutateladze S.S., Leontjev A.I. Heatmasstransfer and friction in the boundary turbulent layer. Energia: Moscow: 342 pp, 1972. (in Russian).

[4] Thermal and hydraulic design of heat exchange equipment of Nuclear Power Plants. Methodical directions (RD 24.035.05.89). Ministry of heavy and power equipment. - I.I.Polzunov Central Boiler - Turbine Research and Design Institute: Leningrad, 210 pp, 1990. (in Russian).

[5] Design of Fuel Handling and Storage Systems for Nuclear power Plants: Safety Guide, Safety Standards Series No NS-G-1,4, IAEA: Vienna, August 2003.

[6] Quality Assurance for Safety in Nuclear Power Plants and other Nuclear Installations: Safety Series No 50-C/SG-Q, IAEA: Vienna, 1996.

[7] Petukhov B.S., Strigin B.K. Turbulent flow and heat transfer in tubes under the significant influence of the thermogravitational forces. Proceedings of the International Seminar on turbulent free convection, Dubrovnik, Yugoslavia, p.701, 1976. (in English).

[8] Kutateladze S.S. Fundamentals of Heat Transfer. Atomizdat: Moscow, $5^{\text {th }}$ ed, 415pp, 1979. (in Russian); E. Arnold Publishers and New York, Academic Press Inc.,: London, $3^{\mathrm{d}}$ ed, 1963. (in English).

[9] Petukhov B.S., Poljakov A.F. Heat transfer by mixed turbulent convection. Nauka: Moscow, 192 pp, 1986. (in Russian).

[10] Petukhov B.S., Strigin B.K. Experimental study of heat transfer by viscous - inertia - gravitational flow of liquid in vertical tubes. Teplophysica vysokih temperature (High temperature thermophysics), vol.6, No 5, p. 933-937, 1968. (in Russian and in English).

[11] Martynenko O.G., Sokovishin Yu. A. Free - convectional heat transfer (Hand book). Nauka I Tehnika: Minsk, 388 pp, 1983. (in Russian).

[12] Petukhov B.S., Kirillov V.V. Heat transfer by the forced convection in tubes. Teploenergetica (Thermal energetics), No. 4, p 63-67, 1958. (in Russian and in English).

[13] Jackson J.D. Influences of buoyancy on velocity, turbulence and heat transfer in ascending and descending flows in vertical passages. Proceedings of $4^{\text {th }}$ Baltic Heat Transfer Conference, Kaunas, Lithuania, 
Aug. 25-27, 2003. “Advances in Heat Transfer Engineering”, ed. B. Sunden, J. Velimas, p. 57-78. (in English).

[14] Petukhov B.S., Genin L.S., Kovaljov S.A. Heat transfer in nuclear power installations. Energoatomizdat: Moscow, 470 pp, 1986. (in Russian).

[15] Kirillov P.L. et al. Methodical directions and recommendations for the thermohydraulic design of the fast reactors active zones (RTM 16.04.008.88) A.I. Leypunsky Institute of Physics and Energetics: 435pp, 1989. (in Russian).

[16] Gotovsky M.A., Fedorovich E.D., Fromzel V.N., Shleifer V.A. Heat transmission of the vertical heat generating rods bundle by the absence of coolant circulation. Inzhenerno-physichesky zhurnal (Journal of Engineering Physics), Minsk, vol. XVI No. 4 p. 363-370, 1984. (in Russian and in English).

[17] Arefiev K.M., Averkiev A.G., Physical peculiarities of the heatmasstransfer by evaporative water cooling. Izvestia VNIIG (Proceedings of All - Union Hydrotechnics Institute), vol.115, p. 81-86, 1977. (in Russian).

[18] Tveiten B., Kersting W., Karpov A. Russian Weapons Plutonium and the Western Option. Nuclear Disarmament Forum AG. Zug, Switzerland: 199pp., 2002. (in English). ,

[19] Arefiev K.M., Fedorovich E.D. Problems of heatmasstransfer study in water pools for the nuclear power plants spent fuel storage. Proceedings of the XIII School - Seminar leading by Prof. A.I. Leontjev, Moscow Power Institute: Moscow, vol.2, p. 412-419, 2001. (in Russian and in English). 